\title{
Detecting 2020 Coral Bleaching Event in the Northwest Hainan Island Using CoralTemp SST and Sentinel-2B MSI Imagery
}

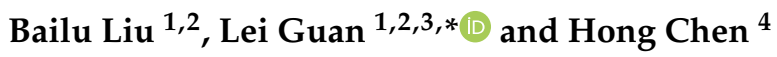 \\ 1 College of Marine Technology, Faculty of Information Science and Engineering, Ocean University of China, \\ Qingdao 266100, China; bailu0126@stu.ouc.edu.cn \\ 2 Sanya Oceanographic Institution, Ocean University of China, Sanya 572024, China \\ 3 Laboratory for Regional Oceanography and Numerical Modeling, Qingdao National Laboratory for Marine \\ Science and Technology, Qingdao 266237, China \\ 4 Hainan South China Sea Institute of Tropical Ocean, Sanya 572024,China; chenhong68@vip.163.com \\ * Correspondence: leiguan@ouc.edu.cn
}

Citation: Liu, B.; Guan, L.; Chen, H. Detecting 2020 Coral Bleaching Event in the Northwest Hainan Island Using CoralTemp SST and Sentinel-2B MSI Imagery. Remote Sens 2021, 13, 4948. https://doi.org/ $10.3390 /$ rs13234948

Academic Editors: José C.B. da Silva, Caixia Wang and Jorge M. Magalhaes

Received: 6 October 2021

Accepted: 3 December 2021

Published: 6 December 2021

Publisher's Note: MDPI stays neutral with regard to jurisdictional claims in published maps and institutional affiliations.

Copyright: (c) 2021 by the authors. Licensee MDPI, Basel, Switzerland. This article is an open access article distributed under the terms and conditions of the Creative Commons Attribution (CC BY) license (https:/ / creativecommons.org/licenses/by/ $4.0 /)$.
Abstract: In recent years, coral reef ecosystems have been affected by global climate change and human factors, resulting in frequent coral bleaching events. A severe coral bleaching event occurred in the northwest of Hainan Island, South China Sea, in 2020. In this study, we used the CoralTemp sea surface temperature (SST) and Sentinel-2B imagery to detect the coral bleaching event. From 31 May to 3 October, the average SST of the study area was $31.01{ }^{\circ} \mathrm{C}$, which is higher than the local bleaching warning threshold value of $30.33^{\circ} \mathrm{C}$. In the difference images of 26 July and 4 September, a wide range of coral bleaching was found. According to the temporal variation in single band reflectance, the development process of bleaching is consistent with the changes in coral bleaching thermal alerts. The results show that the thermal stress level is an effective parameter for early warning of large-scale coral bleaching. High-resolution difference images can be used to detect the extent of coral bleaching. The combination of the two methods can provide better support for coral protection and research.

Keywords: coral bleaching; sea surface temperature; change detecting; Sentinel-2B MSI

\section{Introduction}

Due to the influence of global warming and human activities, the living environments of coral in the ocean are gradually deteriorating. Large-scale coral bleaching often causes unexpected ecological and economic losses [1,2]. According to survey results in 2018, the average live reef coral coverage in the west of Hainan Island was 9\% [3]. Corals are sensitive to changes in their environment. Under harsh conditions, zooxanthellae are expelled from coral polyps and lose their pigments [4], becoming transparent and ultimately exposing the white calcium carbonate skeleton, a process known as coral bleaching. Compared with the traditional field reef investigations, which require a considerable workforce and resources, satellite remote-sensing technology can provide low-cost large-area datasets and has potential for the wide-scale detection of and warning of coral reef bleaching.

The satellite detection of coral bleaching usually uses indirect environmental parameters or direct imagery detection. Sea surface temperature (SST) is the key environmental parameter and satellite SST data have been applied to detect coral bleaching. The National Oceanic and Atmospheric Administration (NOAA) has been implementing the Coral Reef Watch (CRW) program since 2000 on the basis of their previous studies of coral thermal bleaching $[5,6]$. CRW developed the CoralTemp SST dataset and products for coral bleaching thermal stress detection, such as hotspot and degree heating week (DHW), etc. They are widely used in global coral reef monitoring and management. However, in the past, field investigation statistics indicated that the coral bleaching thermal threshold of NOAA CRW is unsuitable in some areas $[7,8]$, including the coral reef regions in the South China 
Sea [9]. Therefore, our early studies improved the thresholds of CRW products in the South China Sea based on 180 cases of historical coral bleaching reports [10].

Coral bleaching detection methods based on satellite imagery generally include change detection and benthic classification. The classification method based on spectral characteristics [11] has high detection accuracy but needs a large amount of field data support and is limited in the process of responding to sudden bleaching events, whereas the change detection method is based on the premise that coral reefs exist in a known area, using images of different phases to directly compare and then infer the coral bleaching area. Ledrew et al. [12] used the spatial autocorrelation coefficient changes in multitemporal satellite imagery to identify the health status of corals based on the spatial heterogeneity of healthy and bleaching coral reef systems. Elvidge et al. [13] used normalized radiometric corrected IKONOS images to create color difference images to detect coral bleaching. Hedley et al. described the coral bleaching events of the Great Barrier Reef in 2016-2017 using spectral reflectance changes in Sentinel-2A imagery at different times [14]. With the development of satellite sensors, satellite data with higher spatial-temporal and spectral resolution aid in monitoring the development process of coral reef bleaching events through change detection.

A severe coral bleaching event occurred along the northwestern coast of Hainan Island in the South China Sea in summer 2020. In this study, combined with coral bleaching thermal stress and Sentinel-2B difference imagery, the coral bleaching distribution in the study area was detected, and the development process of the event is described. Two methods on the remote-sensing detection of coral bleaching by thermal stress warning and difference image detection were analyzed and compared.

\section{Data and Methods}

\subsection{Study Area}

The coast of Hainan Island includes the best-developed fringing reef in China, with a total area of 140.04 square kilometers [3]. Fringing reef grows and develops along the shores of continents or islands, generally in strips or bands [15]. The red box area in Figure 1a is the coverage area of Sentinel-2B imagery selected in this study. The yellow box area subset in Figure 1b is the research area, which is located in the northwest of Hainan Island, along the coast of Paipu Town, Danzhou City, as shown in Figure 1c.

The field investigation showed that severe coral bleaching occurred in this area in summer 2020 (Figure 2). The field survey method in this study is mapped quadrats [16]. For the area with high coral coverage, we used nylon line to produce the $10 \times 10 \mathrm{~m}$ quadrats and subdivided them equally into $2 \times 2 \mathrm{~m}$ squares. Figure 3 shows part of the quadrat. All corals in quadrats were photographed with a camera. We counted from the photos to calculate the bleaching rate, mortality rate, algal coverage after coral death, and the total number of corals. For areas with low coral coverage, we directly counted to calculate the coral bleaching rate, mortality rate, and algal coverage after coral death. The field investigations were carried out on 23 August, 15 September and 17 November. According to the field observations, the coral bleaching rate ranged from $86 \%$ to $98 \%$, and the comprehensive bleaching rate was $92 \%$. The coral bleaching rate refers to the ratio of bleaching corals to the total number of the corals at each quadrat. The comprehensive bleaching rate is the ratio of all bleaching corals sampled at all stations to the total number of all corals sampled at all stations. The main coral species distributed in the study area are Galaxea astreata, Porites lutea, and Favites. The depth of the corals is about $1.5-3 \mathrm{~m}$. The mortality rate of bleached corals was 3\% during the investigation, and Acropora was the main impacted coral. 
(a)

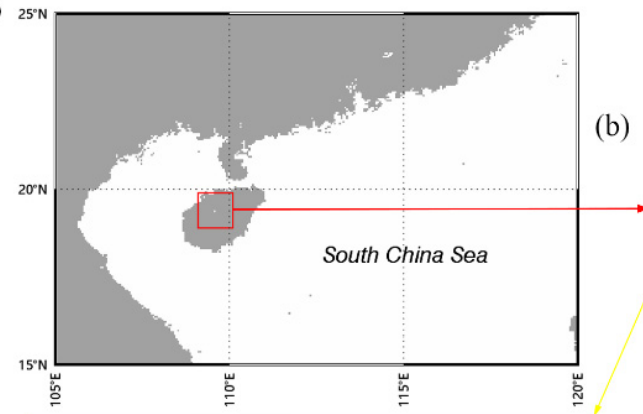

(c)
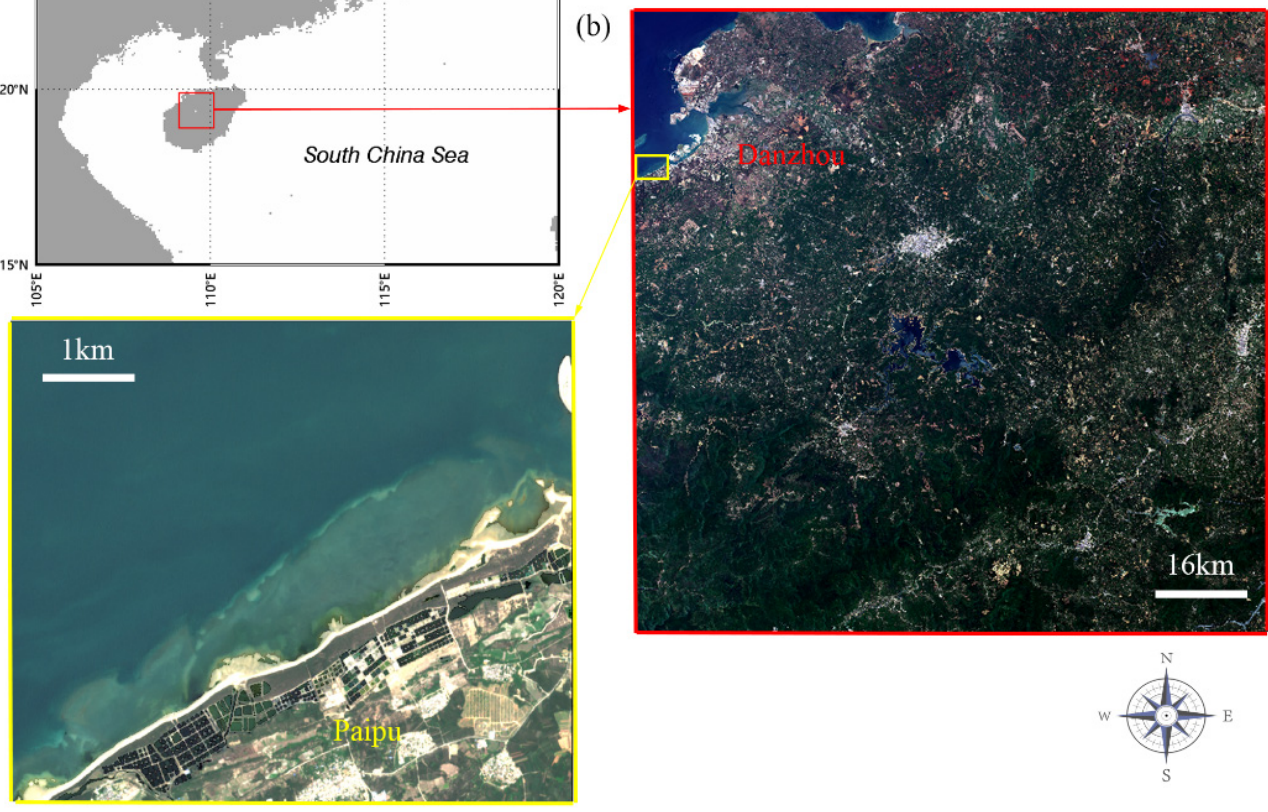

Figure 1. (a) Map of northern South China Sea; (b) whole Sentinel-2B L2A image selected in this study includes the study area in the yellow box; (c) study area location on the coast of Paipu town, Danzhou city.

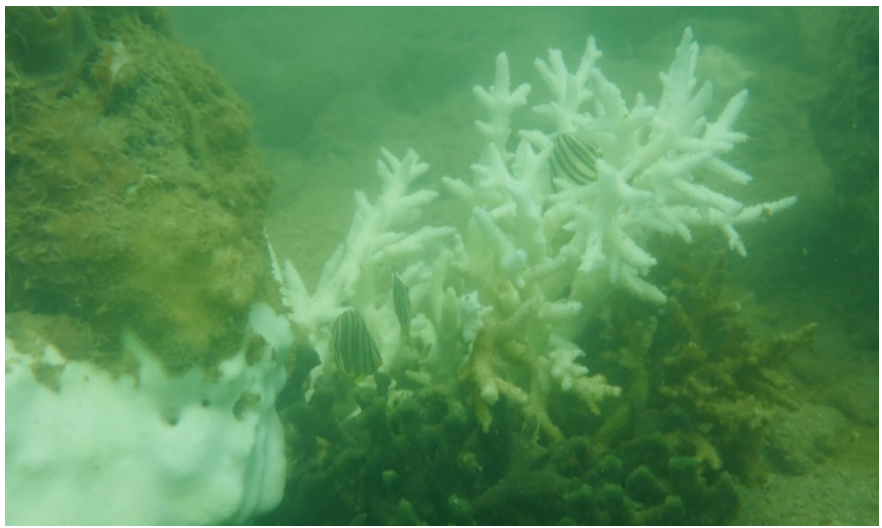

(a)

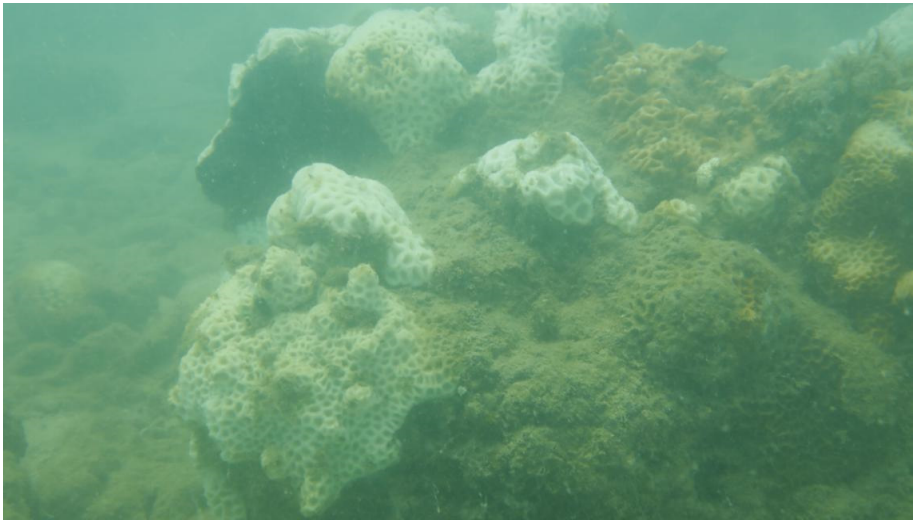

(b)

Figure 2. Coral bleaching on the Paipu coast. (a) Acropora, 23 August 2020; (b) Favites, 15 September 2020.

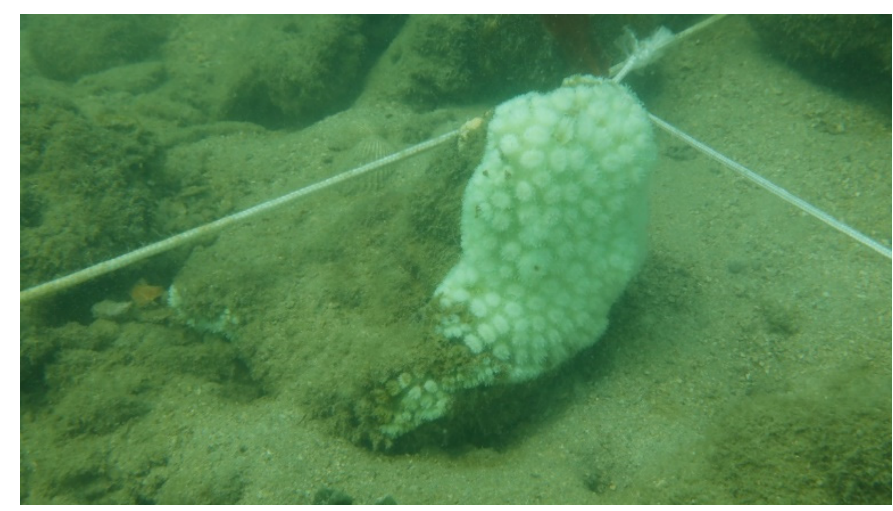

Figure 3. Quadrat corner. Bleaching coral is Galaxea astreata. 15 September 2020. 


\subsection{Data}

\subsubsection{CoralTemp SST Dataset}

In order to obtain stable climatology and coral bleaching thermal stress products based on SST, a long-term, high-quality SST dataset is required. In this regard, NOAA conducted a long-term study and developed daily global $5 \mathrm{~km}$ Geo-Polar SST product [17-19], known as CoralTemp. The dataset used in this study was CoralTemp version 3.1, produced and published by the NOAA National Environmental Satellite, Data, and Information Service (NESDIS) [20]. It can be downloaded from the following website: Ftp://ftp.star.nesdis. noaa.gov/pub/sod/mecb/crw/data/coraltemp/ (accessed on 9 September 2021).

\subsubsection{Sentinel-2B/MSI Data}

In previous research, the main data sources for satellite coral bleaching detection included multispectral imagery, such as IKONOS, WorldView-2, QuickBird, and Landsat. High-spatial-resolution imagery better reflects spatial heterogeneity, but the cost of commercial satellite imagery acquisition restricts its wide application for monitoring and detecting large-scale coral reefs [14].

Landsat-series satellites are available free of charge and are widely used in global coral reef monitoring, but the spatial resolution of $30 \mathrm{~m}$ limits their monitoring accuracy.

Sentinel-2 is part of the Copernicus program led by the European Commission and the European Space Agency (ESA). Two satellites, Sentinel-2A and 2B, each with a revisit time of 10 days, are in orbit. Together, the two satellites provide imagery with a maximum of 5 days of revisit [14], and the data are available on the ESA website: https://scihub. copernicus.eu/dhus/\#/home (accessed on 9 September 2021).

To ensure the consistency of data sources, only data from the Sentinel-2B satellite were selected for our study. The multi-spectral instrument (MSI) onboard the Sentinel-2B satellite has four bands with $10 \mathrm{~m}$ spatial resolution. The specifications of Sentinel-2B/MSI are shown in Table 1 [21].

Table 1. Sentinel-2B MSI specifications.

\begin{tabular}{cccc}
\hline Band & Central Wavelength $(\mathbf{n m})$ & Spatial Resolution $(\mathbf{m})$ & Band Width $(\mathbf{n m})$ \\
\hline 01 & 442.2 & 60 & 21 \\
02 & 492.1 & 10 & 66 \\
03 & 559.0 & 10 & 36 \\
04 & 665.0 & 10 & 31 \\
05 & 703.8 & 20 & 16 \\
06 & 739.1 & 20 & 15 \\
07 & 779.7 & 20 & 20 \\
08 & 833.0 & 10 & 106 \\
$8 \mathrm{a}$ & 864.0 & 20 & 22 \\
09 & 943.2 & 60 & 21 \\
10 & 1376.9 & 60 & 30 \\
11 & 1610.4 & 20 & 94 \\
12 & 2185.7 & 20 & 185 \\
\hline
\end{tabular}

Sentinel-2 L1C products undergo geographic projection, geometric correction, radiation correction, and resampling. On this basis, L2A products undergo atmospheric correction, and the bottom-of-atmosphere (BOA) reflectance for each band is ultimately obtained. Therefore, in this study, L2A data were used for subsequent processing.

\subsection{Coral Bleaching Thermal Stress Calculation}

SST anomaly refers to the difference between the current SST and the climatological SST. When using thermal stress to detect coral bleaching, the upper limit of SST for determining the occurrence of heat bleaching needs to be based on the local mean SST during the hottest period. Therefore, instead of using the long-term mean climatological SST, the climatological benchmark needs to choose the maximum monthly mean (MMM) 
sea temperature. MMM is calculated by first obtaining the long-term monthly mean local sea temperature for 12 months, and then selecting the maximum from the 12-month mean sea temperature.

MMM was calculated in this study using the CoralTemp SST dataset from 1985 to 2019. In order to ensure that results of the new datum were consistent with those of the past, referring to the NOAA CRW reference [22,23], climatological data were re-centered with the following expression:

$$
T_{85-19}=T_{85-93}-\text { slope } \times\left(t_{85-19}-t_{85-93}\right)
$$

where $T$ is the climatology, $t$ is the year of the time center, and slope is the long-term rate of change in the mean monthly sea temperature. Subscripts refer to years and indicate the two periods before and after recentralization.

Parameters to detect coral bleaching thermal stress include hotspot and degree heating week (DHW). Hotspot is a positive anomaly relative to $M M M$ climatological data; the unit is degrees Celsius $\left({ }^{\circ} \mathrm{C}\right)$, and subscript daily represents every single day [18]:

$$
\text { hotspot }=\left\{\begin{array}{cc}
S S T_{\text {daily }}-M M M, S S T_{\text {daily }}>M M M \\
0, & S S T_{\text {daily }} \leq M M M
\end{array}\right.
$$

Thermal stress is one of the reasons for coral bleaching. In addition to the effect of short-term heat stress, studies found that long-term heat accumulation is an important factor contributing to bleaching, and this feature can more effectively reflect the large-scale process of coral bleaching [6].

The DHW index is the cumulative sea temperature thermal anomalies (hotspots) in the last 12 weeks, i.e., Expression (3); the unit is ${ }^{\circ} \mathrm{C}$-weeks [17]. To prevent false high DHW due to the long-term accumulation of low heat, it only accumulates hotspots that exceed the bleaching threshold. Based on the degree of hotspots and DHW, the level of coral bleaching thermal stress in an area can be determined, and the bleaching alert threshold can be used to determine whether the bleaching alert level has been reached or not. The results of our previous studies indicate that through the optimization of critical threshold (CT, the optimal threshold for bleaching warning) and alert threshold (AT, the corresponding threshold for bleaching alarm), the bleaching warning accuracy (ACC) in the South China Sea can be improved from $58.13 \%$ to $73.90 \%$, the false negative rate (FNR) and the false positive rate (FPR) will be less than $30 \%$, the optimal threshold for bleaching warning in the South China Sea region is $0.68^{\circ} \mathrm{C}$, and the corresponding threshold for bleaching alarm is $2.87^{\circ} \mathrm{C}$-weeks [10].

$$
D H W=\frac{1}{7} \sum_{\mathrm{i}=1}^{84}\left(\text { hotspot }_{\mathrm{i}}, \text { if hotspot } \mathrm{i} \geq 0.68{ }^{\circ} \mathrm{C}\right)
$$

Table 2 shows the specific evaluation criteria for bleaching thermal stress levels. The place should be paid attention to, starting with hotspot there greater than zero. When the hotspot is greater than the warning threshold of $0.68^{\circ} \mathrm{C}$, the size of $D H W$ will used to judge the possibility of bleaching. Under $2.87^{\circ} \mathrm{C}$-weeks, bleaching is possible; over $2.87^{\circ} \mathrm{C}$-weeks, bleaching is likely.

Table 2. Definition of coral bleaching thermal stress level.

\begin{tabular}{ccc}
\hline Thermal Stress Levels & Definition & Impact \\
\hline No stress & Hotspot $\leq 0$ & - \\
Watch & $0<$ Hotspot $<0.68$ & - \\
Bleaching warning & Hotspot $\geq 0.68$, DHW $<2.87$ & Possible bleaching \\
Bleaching alert & Hotspot $\geq 0.68$, DHW $\geq 2.87$ & Bleaching likely \\
\hline
\end{tabular}




\subsection{Sentinel-2B Imagery Processing}

Sentinel-2B L2A imagery is the BOA reflectance that has been processed by the algorithm of atmospheric correction. Therefore, to obtain the difference image, processing mainly includes three parts: solar flare correction, pseudo invariant feature radiation normalization, and difference image composition.

\subsubsection{Solar Glint Correction}

The solar glint caused by the mirror reflection of sunlight on the water surface to the sensor is an important factor affecting the quality of remote sensing images. Therefore, solar glint correction is an important step in satellite imagery preprocessing. Hedley et al. [24] proposed a linear regression method for glint correction that uses the strong absorption of water bodies in near infrared (NIR) bands, calculates the regression coefficient using the reflectance of the near infrared band and the band to be corrected in the sample area, and deglints on this band image.

$$
R_{i}^{\prime}=R_{i}-b_{i} \times\left(R_{N I R}-\operatorname{Min}_{N I R}\right)
$$

where $b$ is the regression coefficient; $R$ is the reflectance; subscript $i$ denotes each point to be corrected; $R_{i}$ and $R_{i}{ }^{\prime}$ denote the reflectance before and after correction, respectively; and $\operatorname{Min}_{\text {NIR }}$ is the minimal reflectivity in the NIR band of the sample area.

Sentinel-2B/MSI contains three spatial resolution bands, of which the resolutions of bands $02,03,04$, and 08 are all $10 \mathrm{~m}$ (Table 1). Bands 02, 03, and 04 are visible bands. Band 08 is the NIR band that can be used to correct solar glint in these visible bands. A diagram of flare correction is shown in Figure 4, in which the scatter is BOA reflectance in bands 08 and 02 of the sample area, and the correction factor can be obtained by linear regression.

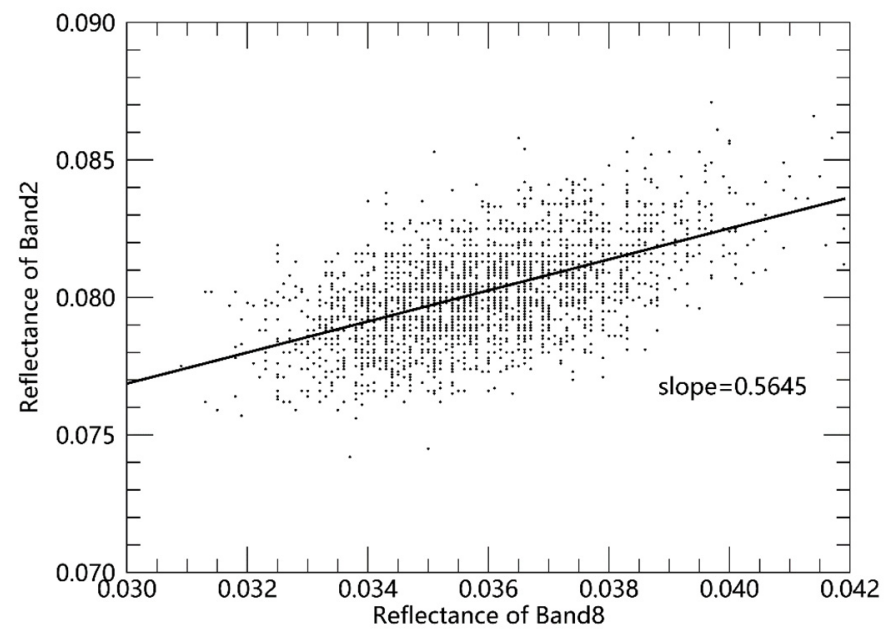

Figure 4. Linear regression between 08 and 02 bands' reflectance on 7 May 2020.

\subsubsection{Pseudo-Invariant Feature Radiation Normalization}

Radiation normalization based on pseudo-invariant features (PIFs) in images was first proposed by Schott et al. [25]. Sample points (PIFs) from remote sensing images with stable spectral properties and no change in the type of objects are selected. Next, normalization correction was performed using the linear relationship of radiation intensities in the same feature point at different times.

In the detection of coral bleaching changes, common pseudo-invariant features include deep water, algae, benthic sandy, white sand on shore, roads, building roofs, etc. The previous study comparison showed that the best normalization results could be obtained from the combination of deep water and white sand $[13,26]$. Therefore, three deep water areas as dark features and two shoreline white sand areas as bright features were selected, each of them including 25 feature points (Figure 5). 


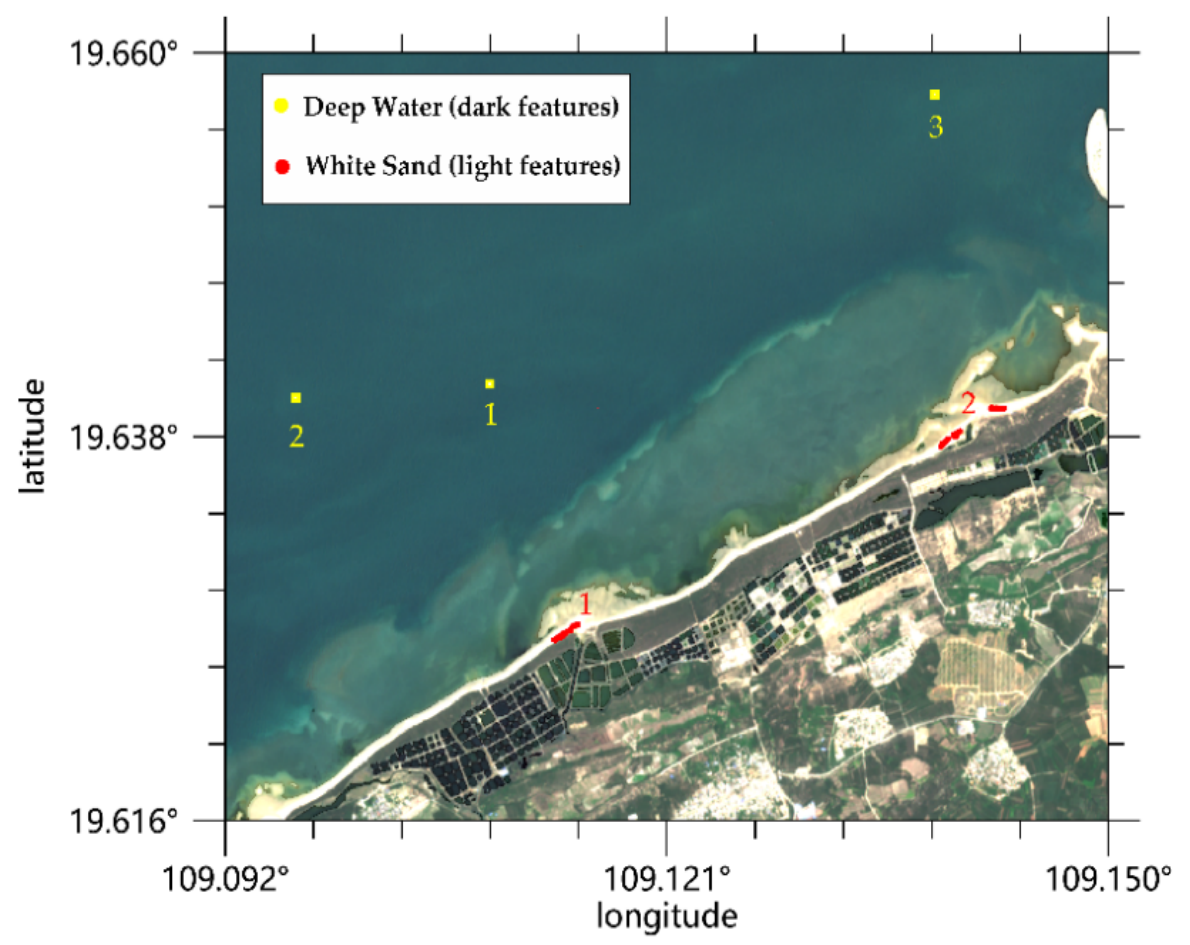

Figure 5. Pseudo invariant feature: 3 deep water (dark features) and 2 white sand (light features) areas, with 25 feature points per location. Positions of pseudo invariant features were randomly selected.

\subsubsection{Difference Imagery Composite}

As corals are bleached, their physical properties change, which leads to changes in the spectral response intensity of each band on satellite sensors. Bleaching corals double their reflectivity compared to healthy corals [27]. Li et al. demonstrated that coral bleaching can be detected by using the band reflectance variation of Sentinel-2, with the green spectral band being the most accurate detecting band [28].

Elvidge et al. composed IKONOS difference images with band of blue, green, and red, according to the difference in reflectance before and after bleaching. The BOA reflectance (BOA_R) of blue and green spectral bands is significantly enhanced after coral bleaching, and the red spectral band is weaker due to water absorption. Consequently, the goldenyellow areas in the image are coral bleaching areas [13]. In this study, we used this method to compose the difference imagery of Sentinel-2B. The order of difference imagery bands is MSI band 02,03 , and 04 . The advantage of this method is that it reduces cloud interference because the reflectance of each band of the cloud increases in visible bands, so it appears white in the difference imagery and can be distinguished from the golden-yellow coral bleaching area.

\section{Results and Discussion}

\subsection{Coral Bleaching Thermal Stress}

The MMM SST calculated from the long-term historical SST in the study area is $29.65^{\circ} \mathrm{C}$, and the critical threshold SST for coral bleaching is $30.33^{\circ} \mathrm{C}$ using the method proposed by Liu et al. [10]. Figure 6 describes the maximum of 7 days' coral bleaching thermal stress level, SST, and DHW in study area, and the drawing format refers to CRW [17]. SST exceeded the critical threshold starting on 31 May 2020, and this lasted up to three and a half months. From 31 May to 3 October, the average SST was $31.01^{\circ} \mathrm{C}$ and the peak SST reached $31.91^{\circ} \mathrm{C}$. Correspondingly, with the accumulated heat, DHW exceeded the alarm threshold of $2.87^{\circ} \mathrm{C}$-weeks [10] on June 16 and remained at the bleaching alarm level until 5 October. The peak DHW reached $18.5^{\circ} \mathrm{C}$-weeks. 


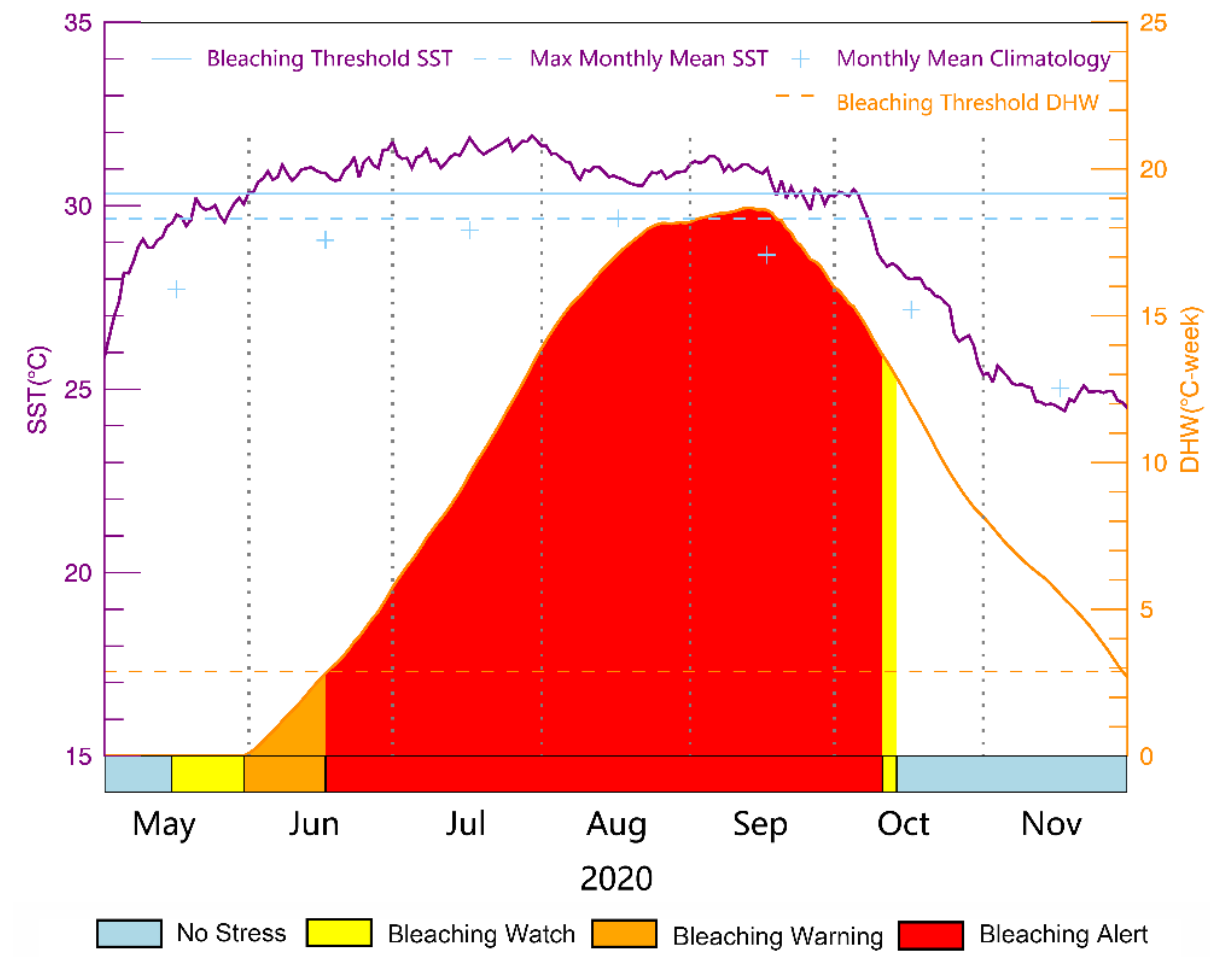

Figure 6. Maximum of 7 days coral bleaching thermal stress level, SST, and DHW from May to November 2020.

The long-term abnormally high sea temperature is an important reason for this coral bleaching event. Most tropical corals live at the edge of the tolerable upper sea temperature limit [5], which makes it difficult for them to quickly adapt to acute sea temperature increases.

\subsection{Bleaching Area Analysis of Difference Image}

After cloud cover screening (<20\%), seven images of Sentinel-2B in 2020 were selected, and the satellite pass local time was 11:05 a.m. The dates of the images are 7 May, 6 June, 6 July, 26 July, 4 September, 4 October, and 13 November 2020.

The Hedley method [22] was used to correct the solar glint in the visible light bands of each scene. Figure 7 contains the RGB images of 7 May 2020, before and after the glint correction; the white box area in Figure $7 \mathrm{a}$ is the sample area. Figure $7 \mathrm{~b}$ shows that the wavy flares in the original image were essentially removed after correction.

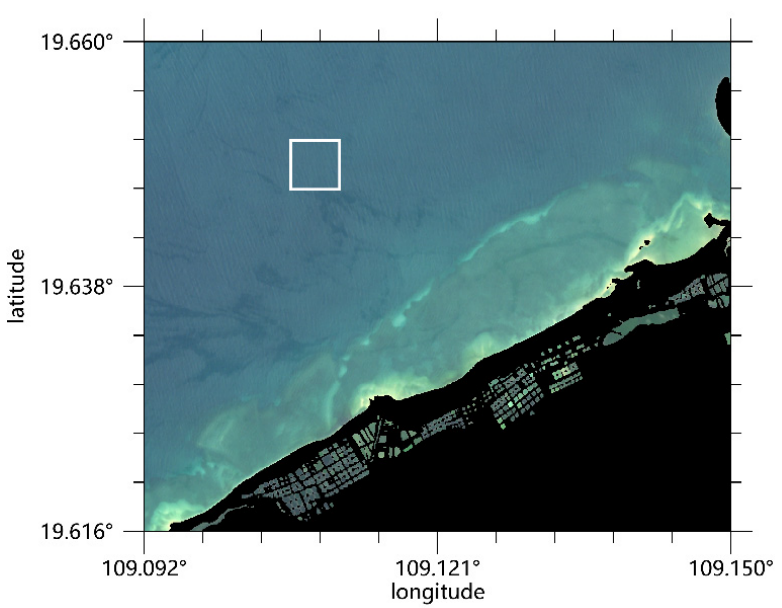

(a)

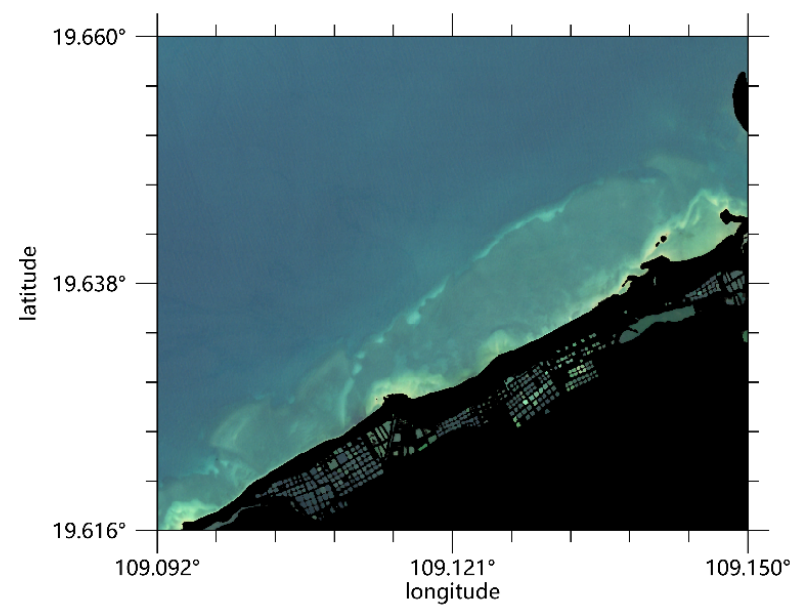

(b)

Figure 7. Images from 7 May 2020 (a) before and (b) after solar glint correction; white box area (left) is sample area. 
Radiation normalization using PIFs was performed on the basis of the image from 7 May 2020. Water depth was about 1.5 to $3 \mathrm{~m}$. Band 02 radiation normalization diagrams between 7 May 2020, and 26 July 2020 are shown in Figure 8. BOA_R had an obvious linear correlation between the two dates, which proves that the appropriate pseudo-invariant feature point has been selected. Normalization can also satisfy the need for producing difference imagery. The normalized results for each visible spectral band of all images and the $\mathrm{R}^{2}$ evaluation are shown in Table 3.

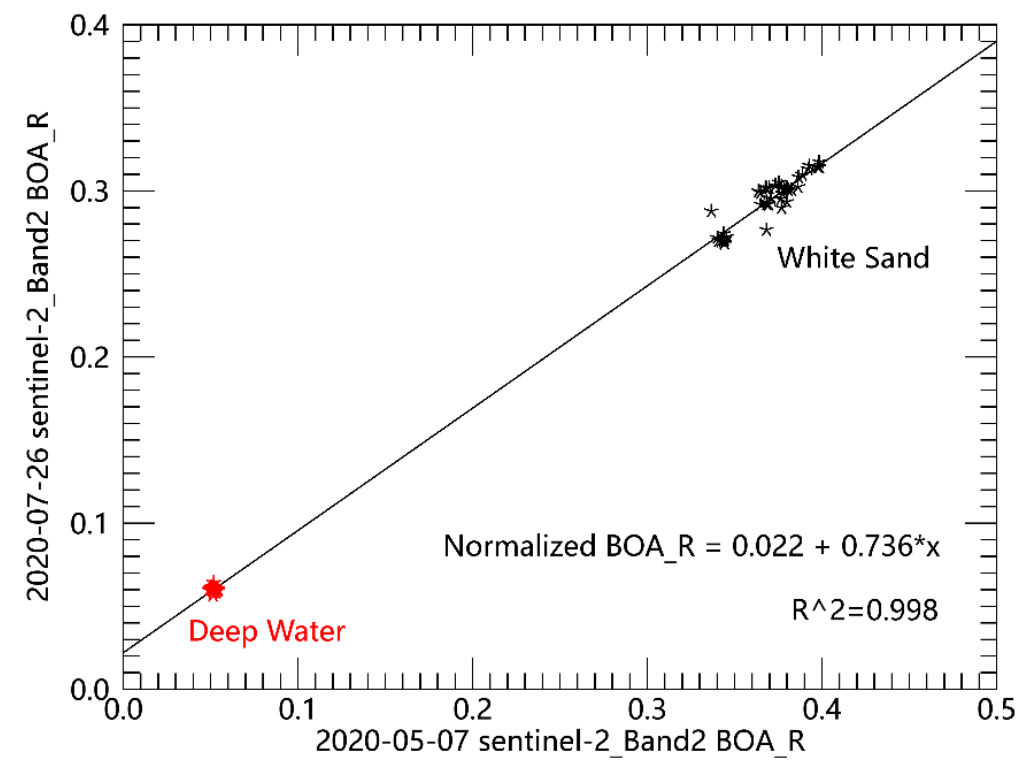

Figure 8. Spectral band 02 normalization for deep water and white sand feature between 7 May 2020, and 26 July 2020.

Table 3. Regression results of reflectance normalization based on 7 May 2020.

\begin{tabular}{cccccccccc}
\hline \multirow{2}{*}{ Date } & \multicolumn{3}{c}{ Band 02 } & \multicolumn{3}{c}{ Band 03 } & \multicolumn{3}{c}{ Band 04 } \\
\cline { 2 - 10 } & Scale & Offset & $\mathbf{R}^{\mathbf{2}}$ & Scale & Offset & $\mathbf{R}^{\mathbf{2}}$ & Scale & Offset & $\mathbf{R}^{\mathbf{2}}$ \\
\hline 6 June 2020 & 0.690 & 0.016 & 0.944 & 0.770 & 0.002 & 0.936 & 0.806 & 0.005 & 0.939 \\
6 July 2020 & 0.702 & 0.040 & 0.982 & 0.766 & 0.032 & 0.988 & 0.822 & 0.027 & 0.991 \\
26 July 2020 & 0.647 & 0.038 & 0.996 & 0.742 & 0.020 & 0.998 & 0.772 & 0.024 & 0.998 \\
4 September 2020 & 0.700 & 0.030 & 0.995 & 0.773 & 0.018 & 0.997 & 0.795 & 0.023 & 0.998 \\
4 October 2020 & 0.824 & 0.023 & 0.945 & 0.863 & 0.016 & 0.956 & 0.870 & 0.030 & 0.962 \\
13 November 2020 & 0.801 & 0.025 & 0.989 & 0.874 & 0.004 & 0.992 & 0.868 & 0.015 & 0.995 \\
\hline
\end{tabular}

The normalized images of bands 02,03 , and 04 were compared with the corresponding bands of 7 May 2020, and the three band differences were then composed into false color images in sequence. Images were enhanced and the result is shown in Figure 9. The goldenyellow part is the area where the blue and green spectral bands' reflectance significantly increased; that is, the coral bleaching area identified by the difference image.

On the basis of difference image results, there was no significant change in the remote sensing reflectance of the coral reef areas on 6 June or 6 July. By 26 July, there were significant areas of coral bleaching. No images were available due to excessive cloud cover in August. The bleaching area on 4 September was larger than that on 26 July. We inferred that the severity of coral bleaching increased from the end of July to September, which is the stage of bleaching development. We found coral bleaching in the field survey in August and September. After comparing with the position of the image (the distance from the shore and the approximate area areal extent of the bleaching), we believe that the golden yellow pixels are actually bleaching corals. According to the field investigation on 17 November, $80 \%$ of dead corals grew algae after bleaching. On 4 October and 13 November, the bleaching detection area significantly decreased. The change was due to bleaching recovery and algae coverage, which is presumed to be in the late bleaching stage. Table 4 shows that 
the areal extent of detected bleaching area was $0.0664,0.1079$ and $0.0041 \mathrm{~km}^{2}$ on $26 \mathrm{July}$, 4 September, and 4 October respectively.
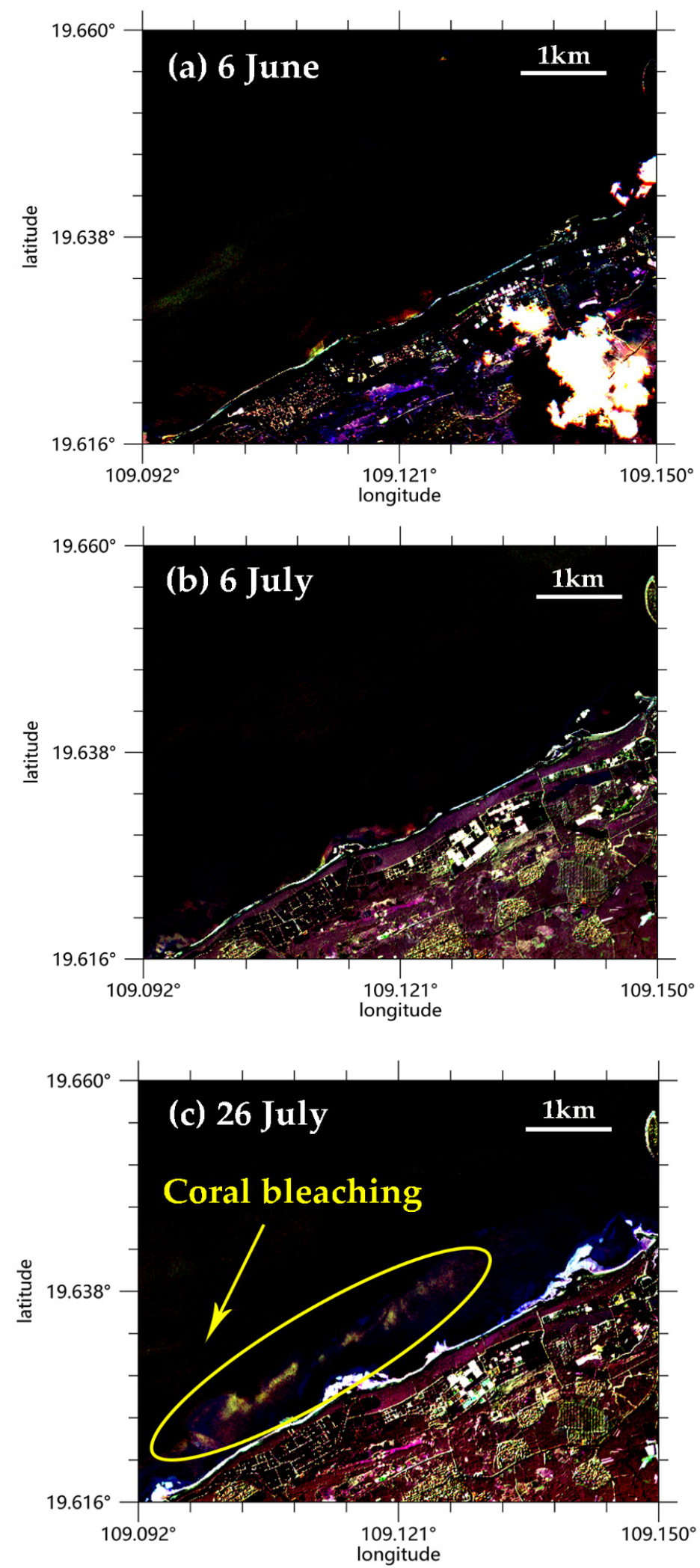

Figure 9. Cont. 

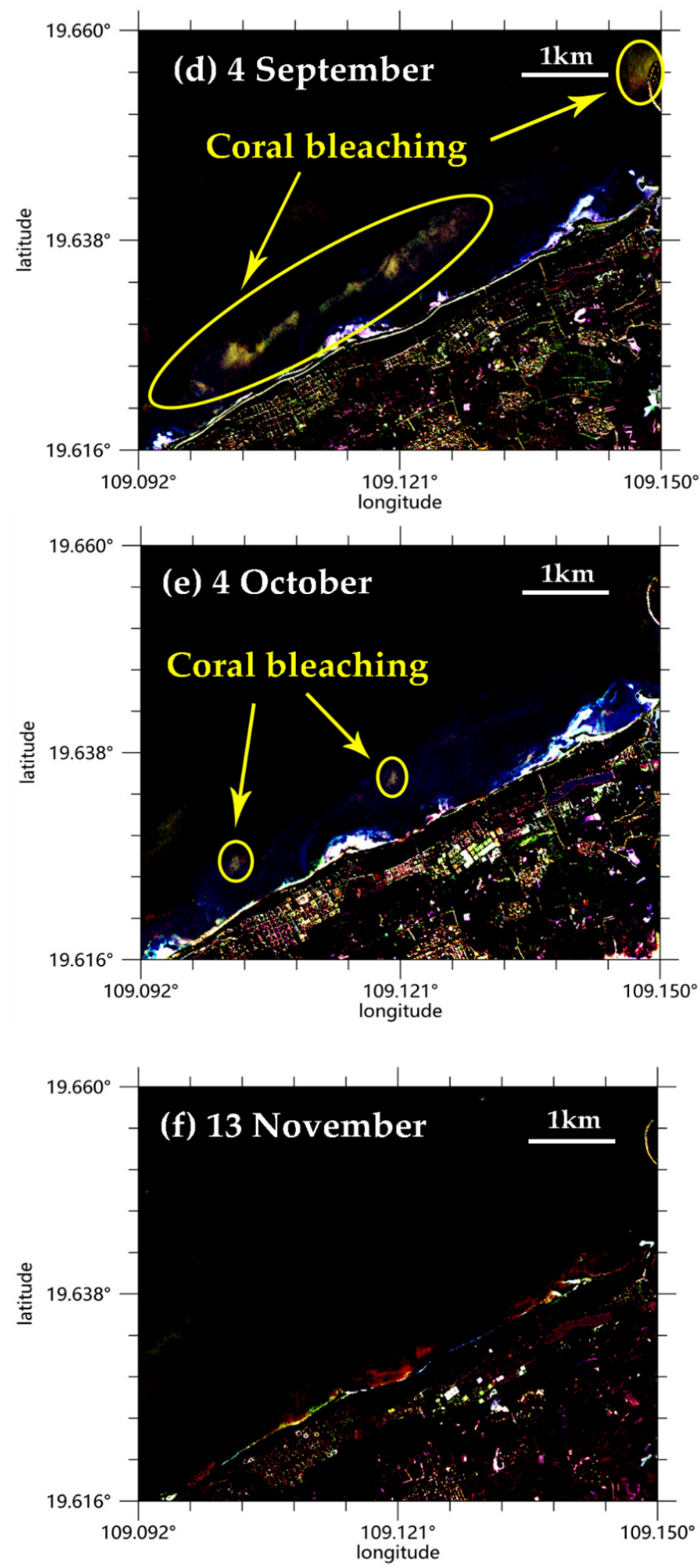

Figure 9. Sentinel-2B normalized difference images of 7 May 2020, and (a) 6 June 2020; (b) 6 July 2020; (c) 26 July 2020; (d) 4 September 2020; (e) 4 October 2020; and (f) 13 November 2020, along the coast of Paipu town, Danzhou city. Golden-yellow part within the ellipse range is the coral bleaching area. 
Table 4. Areal extent of detected bleaching area.

\begin{tabular}{cc}
\hline Date & Detected Bleaching Area $\mathbf{( k m}^{\mathbf{2}} \mathbf{~}$ \\
\hline 26 July 2020 & 0.0664 \\
4 September 2020 & 0.1079 \\
4 October 2020 & 0.0041 \\
\hline
\end{tabular}

Difference image analysis shows that the time period of coral bleaching development coincides with the change in thermal stress level. By 4 October, the high temperature had lasted for nearly four months. The SST has been on a decreasing trend in early October. Notably, bleaching thermal stress entered the highest level of bleaching alert about a month before the apparent reflectance change in the early Sentinel-2B images, which shows that the thermal stress level based on CoralTemp SST is suitable for providing warnings of coral bleaching events on the north-western coast of Hainan.

\subsection{Normalized Reflectance of Bleaching Area}

In addition to the qualitative analysis of coral bleaching areas, the green band of Sentinel-2 MSI can be effectively used to detect coral bleaching on the change in its reflectance after radiation normalization [14].

As shown in Figure 10, the band 03 BOA_R changes on different dates in the bleaching region shows an upward trend from May to September, which corresponds to the occurrence and development of coral bleaching. The bleaching response (increased reflectivity) was strongest in early September and significantly decreased in October, consistent with the analysis of the difference images. Given previous analysis of the Sentinel-2 endmember reflectance spectra [29], the reflectance may decrease obviously when its state changes. The reflectance results on 4 October obviously decreased, and the median reflectivity on 13 November was significantly lower than before, suggesting that there was a high probability of coral recovery, algal cover increase, and even coral death after the coral bleaching event.

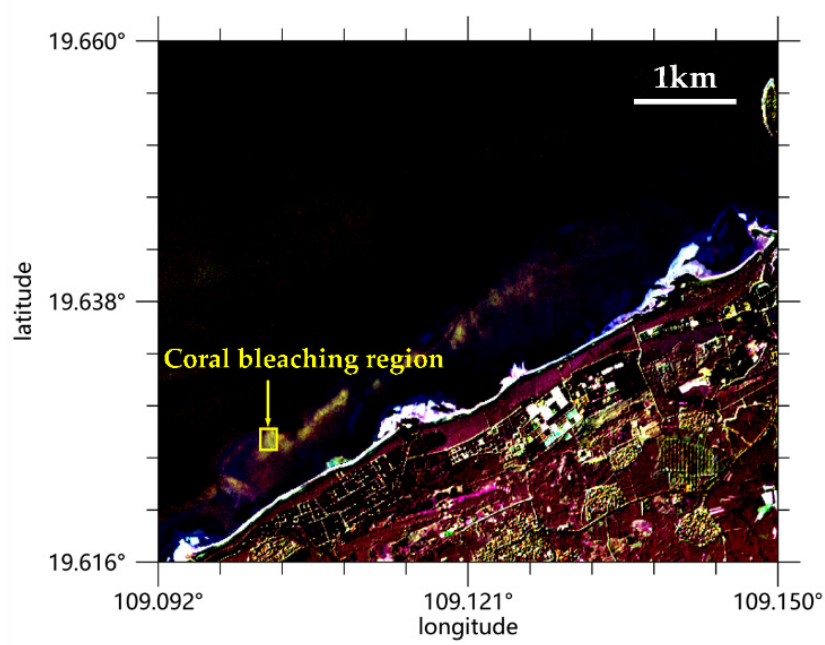

(a)

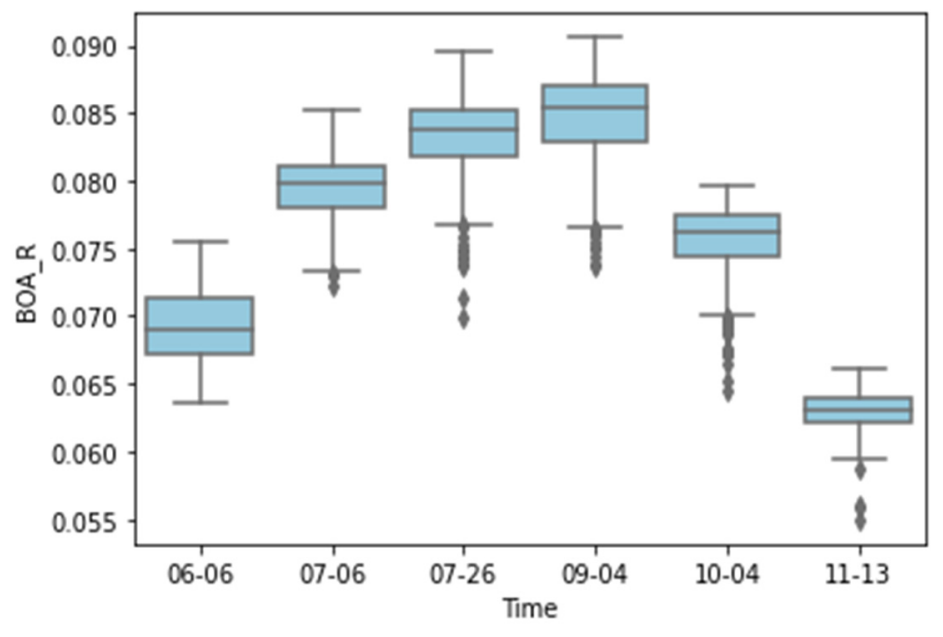

(b)

Figure 10. (a) Coral bleaching region on 26 July 2020. (b) Normalized Band3 BOA_R changes for coral bleaching region.

\section{Conclusions}

Based on the difference image of CoralTemp SST and Sentinel-2B imagery, coral bleaching events in the northwest of Hainan Island in the South China Sea were detected. Results showed that large-scale coral bleaching occurred in the study area in summer 2020. We verified the feasibility of using thermal stress parameters for coral bleaching warning. 
From the end of May to the beginning of October 2020, SST exceeded the bleaching warning threshold for about 4 months, and the peak sea temperature was about $31.91^{\circ} \mathrm{C}$. Cumulative heat dramatically increased, and the peak DHW reached $18.5^{\circ} \mathrm{C}$-weeks. Therefore, we inferred that the high intensity of the SST anomaly was an important reason for this coral bleaching event.

High-resolution difference imagery shows that many corals in the study area experienced bleaching in late July and early September 2020. Temporal variation in the difference image and single-band reflectance could reflect the occurrence and development of the event. Coral reefs in this area may have experienced bleaching in July, and the bleaching degree enhanced from the end of July to September. In October, the bleaching area significantly decreased. Based on the field survey in November, some dead corals were covered by algae, and most corals recovered from bleaching. Results show that coral bleaching can be effectively detected by the normalized Sentinel-2B difference imagery. The short revisit time of Sentinel-2 provide chances for rapid detections of new bleaching events and observations of the occurrence, development and disappearance of bleaching cycle through difference images.

Overall, SST can be combined with high-spatial-resolution remote sensing images to achieve early warning and monitoring of the development of coral bleaching. The application of satellite remote sensing observations to coral bleaching detection can provide support for coral reef ecosystem protection and field investigation.

Author Contributions: Conceptualization, B.L. and L.G.; methodology, B.L.; data processing, B.L.; formal analysis, B.L., L.G. and H.C.; field investigation, H.C., B.L. and L.G.; writing-original draft preparation, B.L.; writing-review and editing, L.G.; funding acquisition, L.G. and H.C. All authors have read and agreed to the published version of the manuscript.

Funding: The research was supported by the Finance Science and Technology Project of Hainan Province under grant ZDYF2020010 and ZDYF2019117, and the National Program on Global Change and Air-Sea Interaction under grant GASI-02-PACINDYGST2-03.

Data Availability Statement: NOAA Coral Reef Watch Version 3.1 Daily Global 5 km Satellite CoralTemp SST, from 1 January 1985 to 30 November 2020. Data set accessed 9 September 2021 at ftp: / / ftp.star.nesdis.noaa.gov/pub/sod/mecb/crw/data/5km/v3.1_op/nc/v1.0/daily/sst/. Sentinel2B imagery can be downloaded from ESA website (https:/ / scihub.copernicus.eu/dhus/\#/home, accessed on 9 September 2021).

Acknowledgments: The version 3.1 daily global $5 \mathrm{~km}$ satellite SST product CoralTemp was provided by NOAA Coral Reef Watch, and the time-series Sentinel-2B Level-2A MSI products were produced from ESA remote sensing data.

Conflicts of Interest: The authors declare no conflict of interest. The funders had no role in the design of the study; in the collection, analyses, or interpretation of data; in the writing of the manuscript, or in the decision to publish the results.

\section{References}

1. Eakin, C.M.; Sweatman, H.; Brainard, R.E. The 2014-2017 global-scale coral bleaching event: Insights and impacts. Coral Reefs 2019, 38, 539-545. [CrossRef]

2. Sebens, K.P. Biodiversity of Coral Reefs: What Are We Losing and Why? Am. Zool. 1994, 34, 115-133. [CrossRef]

3. Huang, H. Status of Coral Reefs in China (2010-2019), 1st ed.; China Ocean Press: Beijing, China, 2021; pp. 27, 30. (In Chinese)

4. Jaap, W.C. Observations on zooxanthellae expulsion at middle sambo reef, florida keys. Bull. Mar. Sci. Miami 1979, $29,414-422$.

5. Glynn, P.W.; D'Croz, L. Experimental evidence for high temperature stress as the cause of El Niño-coincident coral mortality. Coral Reefs 1990, 8, 181-191. [CrossRef]

6. Berkelmans, R.; Willis, B.L. Seasonal and local spatial patterns in the upper thermal limits of corals on the inshore Central Great Barrier Reef. Coral Reefs 1999, 18, 219-228. [CrossRef]

7. Donner, S.D. An evaluation of the effect of recent temperature variability on the prediction of coral bleaching events. Ecol. Appl. 2011, 21, 1718-1730. [CrossRef] [PubMed]

8. Kumagai, N.H.; Yamano, H. Sango-Map-Project. High-resolution modeling of thermal thresholds and environmental influences on coral bleaching for local and regional reef management. PeerJ 2018, 6, e4382. [CrossRef] [PubMed] 
9. Li, S.; Yu, K.; Chen, T.; Shi, Q.; Zhang, H.L. Assessment of coral bleaching using symbiotic zooxanthellae density and satellite remote sensing data in the Nansha Islands, South China Sea. Chin. Sci. Bull. 2011, 56, 1031-1037. [CrossRef]

10. Liu, B.L.; Guan, L. Improved method of thermal stress detection for coral reef bleaching in the South China Sea. Remote Sens. Nat. Resour. 2021, in press.

11. Purkis, S.J. A "Reef-Up" approach to classifying coral habitats from IKONOS imagery. IEEE Trans. Geosci. Remote Sens. 2005, 43, 1375-1390. [CrossRef]

12. Ledrew, E.F.; Holden, H.; Wulder, M.A.; Derksend, C.; Newman, C. A spatial statistical operator applied to multidate satellite imagery for identification of coral reef stress. Remote Sens. Environ. 2004, 91, 271-279. [CrossRef]

13. Elvidge, C.D.; Dietz, J.B.; Berkelmans, R.; Andrefouet, S.; Skirving, W.; Strong, A.E.; Tuttle, B.T. Satellite observation of Keppel Islands (Great Barrier Reef) 2002 coral bleaching using IKONOS data. Coral Reefs 2004, 23, 123-132. [CrossRef]

14. Hedley, J.D.; Roelfsema, C.; Brando, V.; Giardino, C.; Kutser, T.; Phinn, S.; Mumby, P.J.; Barrilero, O.; Laporte, J.; Koetz, B. Coral reef applications of Sentinel-2: Coverage, characteristics, bathymetry and benthic mapping with comparison to Landsat 8 . Remote Sens. Environ. 2018, 216, 598-614. [CrossRef]

15. Huo, Y.H.; Zhu, L.W.; Zhang, S.Y.; Yang, X.; Tang, S.L. Distributional data of shallow sea coral reef in Danzhou Bay Sanya Coral Reef National Nature Reserve from 1987 to 2018. Sci. Data Bank 2019, 4, 13-25. (In Chinese)

16. Leujak, W.; Ormond, R. Comparative accuracy and efficiency of six coral community survey methods. J. Exp. Mar. Biol. Ecol. 2007, 351, 168-187. [CrossRef]

17. Liu, G.; Heron, S.F.; Eakin, C.M.; Mullerkarger, F.E.; Vega-Rodriguez, M.; Guild, L.S.; De La Cour, J.L.; Geiger, E.F.; Skirving, W.J.; Burgess, T.F.R.; et al. Reef-Scale Thermal Stress Monitoring of Coral Ecosystems: New 5-km Global Products from NOAA Coral Reef Watch. Remote Sens. 2014, 6, 11579-11606. [CrossRef]

18. Skirving, W.; Marsh, B.; Cour, J.; Liu, G.; Eakin, C.M. Coraltemp and the coral reef watch coral bleaching heat stress product suite version 3.1. Remote Sens. 2020, 12, 3856. [CrossRef]

19. Maturi, E.; Harris, A.; Mittaz, J.; Sapper, J.; Wick, G.; Zhu, X.; Dash, P.; Koner, P. A New High-Resolution Sea Surface Temperature Blended Analysis. Am. Met. Soc. 2017, 98, 1015-1026. [CrossRef]

20. Liu, G.; Skirving, W.J.; Geiger, E.F.; De La Cour, J.L.; Marsh, B.L.; Heron, S.F.; Tirak, K.V.; Strong, A.E.; Eakin, C.M. NOAA Coral Reef Watch's 5 km Satellite Coral Bleaching Heat Stress Monitoring Product Suite Version 3 and Four-Month Outlook Version 4. Reef Encounter 2017, 32, 39-45.

21. Multi Spectral Instrument (MSI) Overview. Available online: https://sentinel.esa.int/web/sentinel/technical-guides/sentinel-2msi/msi-instrument (accessed on 29 March 2021).

22. Heron, S.F.; Liu, G.; Eakin, C.M.; Skirv ing, W.J.; Muller-Karger, F.E.; Vega-Rodriguez, M.; De La Cour, J.L.; Burgess, T.F.; Strong, A.E.; Geiger, E.F.; et al. Climatology Development for NOAA Coral Reef Watch's 5-km Product Suite; NOAA Technical Report NESDIS 145; NOAA/NESDIS: College Park, MD, USA, 2015.

23. Heron, S.F.; Maynard, J.; van Hooidonk, R.; Eakin, C.M. Warming Trends and Bleaching Stress of the World's Coral Reefs 1985-2012. Sci. Rep. 2016, 6, 38402. [CrossRef] [PubMed]

24. Hedley, J.D.; Harborne, A.R.; Mumby, P.J. Technical note: Simple and robust removal of sun glint for mapping shallow-water benthos. Int. J. Remote Sens. 2005, 26, 2107-2112. [CrossRef]

25. Schott, J.R.; Salvaggio, C.; Volchok, W.J. Radiometric scene normalization using pseudoinvariant features. Remote Sens. Environ. 1988, 26, 1-6. [CrossRef]

26. Rowlands, G.P.; Purkis, S.J.; Riegl, B.M. The 2005 Coral-bleaching Event Roatan (Honduras): Use of Pseudo-invariant Features (PIFs) in Satellite Assessments. J. Spat. Sci. 2008, 53, 99-112. [CrossRef]

27. Holden, H.; Ledrew, E. Spectral Discrimination of Healthy and Non-Healthy Corals Based on Cluster Analysis, Principal Components Analysis, and Derivative Spectroscopy. Remote Sens. Environ. 1998, 65, 217-224. [CrossRef]

28. Li, J.; Fabina, N.S.; Knapp, D.E.; Asner, G.P. The Sensitivity of Multi-spectral Satellite Sensors to Benthic Habitat Change. Remote Sens. 2020, 12, 532. [CrossRef]

29. Hedley, J.; Roelfsema, C.; Koetz, B.; Phinn, S. Capability of the sentinel 2 mission for tropical coral reef mapping and coral bleaching detection. Remote Sens. Environ. 2012, 120, 145-155. [CrossRef] 